\title{
Bionomics of phlebotomine sand flies (Diptera: Psychodidae) in the province of Al-Baha, Saudi Arabia
}

\author{
Said Abdallah Doha ${ }^{1}{ }^{+}$, Abdallah M Samy ${ }^{2}$ \\ ${ }^{1}$ Research and Training Center on Vectors of Diseases ${ }^{2}$ Entomology Department, Faculty of Science, Ain Shams University, Abbassia, Cairo, Egypt
}

The bionomics of phlebotomine sand flies (Diptera: Psychodidae) were studied for two successive years (January 1996-December 1997) at 12 collecting stations representing six sectors of the province of Al-Baha, Saudi Arabia. The predominant species was Phlebotomus bergeroti (41.7\%), followed by lesser numbers of Phlebotomus sergenti $(11 \%)$, Phlebotomus arabicus (10.6\%), Sergentomyia tiberiadis $(10.5 \%)$, Phlebotomus papatasi $(10.2 \%)$, Sergentomyia antennata (9.6\%), Phlebotomus alexandri (3\%), Phlebotomus orientalis $(2.3 \%)$ and Sergentomyia clydei (1.1\%). The distribution of the collected species including species that are elsewhere known to act as vectors of human cutaneous leishmaniasis were distributed across different altitudes in Al-Baha. P. bergeroti, P. papatasi and P. arabicus were more abundant indoors; however, P. sergenti was more abundant outdoors. Sand fly populations exhibited three patterns of seasonal abundance in terms of their monthly activity. P. bergeroti, P. sergenti and P. arabicus were found to be naturally infected with Leishmania-like flagellates at an infection rate of $0.2 \%$.

Key words: Al-Baha - Saudi Arabia - sand fly - bionomics - seasonal abundance

Globally, leishmaniasis is prevalent in 88 countries and affects an estimated 12 million people with approximately two million new cases per year, of which 500,000 are visceral leishmaniasis (VL) and 1,500,000 are cutaneous leishmaniasis (CL) (90\% of them in Afghanistan, Algeria, Brazil, the Islamic Republic of Iran, Peru, Saudi Arabia and Sudan) (WHO 2008).

In Saudi Arabia and neighboring countries, different species of Leishmania cause CL and VL (al-Zahrani et al. 1989). Most cases of CL are caused by Leishmania major. Much less frequently, Leishmania tropica has been found associated with this disease. L. major has been described as the etiological agent responsible for maintenance of the zoonotic transmission cycle of CL. In Saudi Arabia, zoonotic CL (ZCL) is transmitted to humans from infected rodent reservoir hosts (Psammomys obesus and Meriones libycus) through the bites of the sand fly vector Phlebotomus papatasi (Killick-Kendrick et al. 1985).

The occurrence of L. tropica appears to be limited to a small number of settlements in hilly and semi-arid areas (al-Zahrani et al. 1989). However, in recent years, the incidence of $L$. tropica infections has increased throughout the Middle East (Svobodova et al. 2006, Shehata et al. 2009). The transmission cycle of L. tropica is usually anthroponotic, with zoonotic transmission reportedly occurring in some areas (Shehata et al. 2009). Phlebotomus sergenti is often implicated as the sand fly vector in both transmission cycles throughout Middle Eastern countries, including Saudi Arabia (al-Zahrani et al. 1988).

Financial support: Ministry of Health, Al-Baha, KSA

+ Corresponding author: samyasu@aol.com

Received 20 March 2010

Accepted 4 August 2010
Since early surveys of sand flies (Lewis \& Büttiker 1980, Lewis 1982, Büttiker \& Lewis 1983) in Saudi Arabia, few sporadic reports have described sand fly species composition, their geographical distribution and their role in disease dynamics (al-Zahrani et al. 1988, Ibrahim \& Abdoon 2005). Surveys of the sand fly fauna in Saudi Arabia revealed the presence of 25 species (Lewis \& Büttiker 1980, 1982), with dominance of $P$. papatasi in all investigated areas of the kingdom (Mustafa et al. 1994). Leishmaniasis has a wide geographical distribution that coincides with the distribution of the sand fly vector. $P$. papatasi and $P$. sergent $i$ were reported to increase the risk of CL transmission in the area studied in Saudi Arabia (Ibrahim \& Abdoon 2005, El-Badry et al. 2008).

With the increasing incidence of CL caused by $L$. tropica in Al-Baha (Morsy et al. 1991), study of phlebotomine sand flies in Al-Baha is of considerable public health importance, especially if the area has a certain topography and ecosystem. In this study, we carried out an entomological survey to monitor sand fly population density, seasonal abundance and plateaus to understand the role of the sand flies in maintenance of the leishmaniasis-transmission cycle and to predict disease risk factors in the Al-Baha province of Saudi Arabia to further design of vector control strategies.

\section{MATERIALS AND METHODS}

Study area - Al-Baha province is situated between Makkah Al Mukarramah and the Asir region in southwestern Saudi Arabia. It is surrounded by a number of cities, including Taif to the north, Beesha to the east, Abha to the south and the Red Sea coast city of Al Qunfuda to the west. Al-Baha (Fig. 1) is divided into sectors representing different altitudes above sea level: $\geq 2500 \mathrm{~m}$ (Al-Dafear and Al-Baha), 800-1200 m (El Aqiq and El Mandak) and $\leq 200 \mathrm{~m}$ (Al-Mekowa and Khelow). Sampling of sand flies was carried out in 12 villages containing CL cases. 
Twelve collection stations were selected for the current study. The selected stations represent six sectors with the characteristic wild to peridomestic habitats: Al-Dafear (Al-Hamaed, Hezna), Al-Baha (Khefa and Bani-Heda), El Aqiq (Al-Jawa, Al-Wedhia), El Mandak (Al-Nahda and Hadabet Bel Hossien), Al-Mekowa (Al-Mezera) and Khelow (Al-Hareka, Aiase and Al-Hega). Al-Baha province is characterized by natural tree cover and an agricultural plateau. Due to its location, Al-Baha's climate is moderate in the summer and cold in the winter.

Selection of sampling sites - In 1991, physicians from local health units in Al-Baha identified hundreds of patients with characteristic CL. The presence of these cases prompted the primary health unit in Al-Baha to survey the local sand fly fauna in order to identify vector species responsible for disease transmission in selected endemic villages representing different sectors of Al-Baha.

Sand fly collection and processing - Sand flies were collected during the period from January 1996-December 1997. Three collection methods were used. The first utilized CDC miniature light traps (John W Hock Co, Gainesville, FL, USA) (1,440 trap-nights). The traps were set $1 \mathrm{~h}$ before sunset and collected after sunrise next morning. The second and third methods were aspiration from protected human volunteers both inside and outside houses $(576$ volunteer-hours) and the use of sticky paper traps $(14,400$ trap-nights). Collected flies were preserved in $70 \%$ alcohol, cleaned in chloral hydrate: phenol $(1: 1 \mathrm{v} / \mathrm{v})$ and then mounted in Puri's medium (Smart et al. 1965) for identification using several characteristics (Lewis \& Büttiker 1980, Lewis 1982, Büttiker \& Lewis 1983, Lane 1986). The number of sand flies from each species was scored to estimate the seasonal abundance in all the areas sampled. Sand flies attempting to land on the bed nets of protected hu-

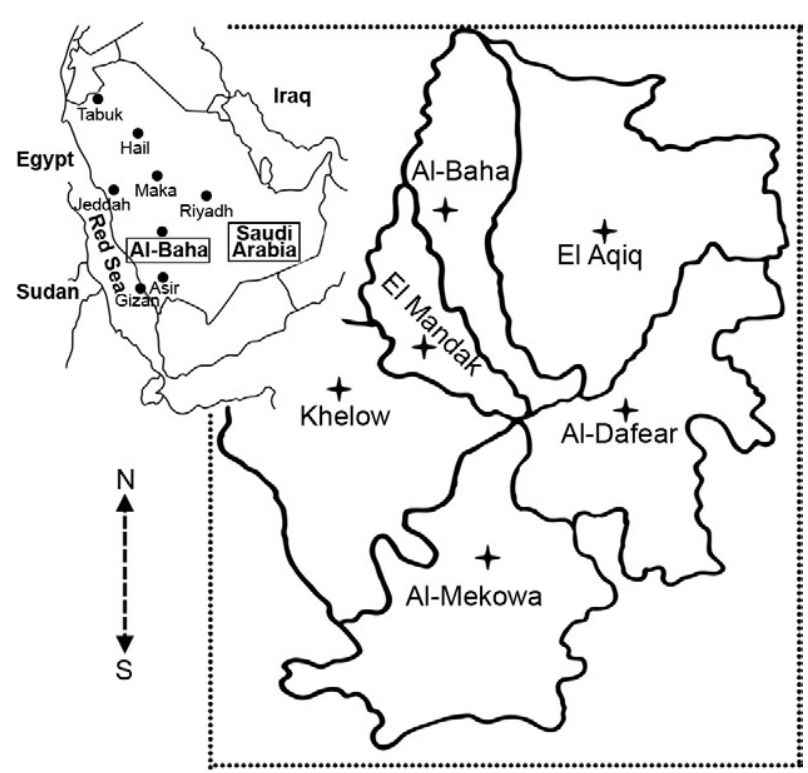

Fig. 1: the map of study area showing different sectors inside of the province of Al-Baha, Saudi Arabia. Al-Baha province is denoted by dashed rectangular. man volunteers were collected by aspirator and numbered for an estimation of the landing rate of each species. Live females were immobilized on ice and dissected in $0.9 \%$ sterile saline on a glass slide by making an incision at the base of the abdomen, expelling the entire gut and placing a cover slip on top of the fly. Mounted flies were then microscopically examined for Leishmania infection under an oil-immersion lens (100X). Females dissected in this way remained intact after having their ovaries dissected so that parous and nulliparous females could be differentiated; this procedure is in accordance with the method applied by Ungureanu (1974) and applied by Ibrahim and Abdoon (2005). Aside from this dissection, the female flies were left intact. The genitalia and mouthparts of all dissected females were then mounted for identification.

Statistical analysis - The sand fly data was analyzed using SAS JMP Statistical Discovery v8.0.2. The Shannon-Weiner $(\mathrm{H})$, evenness $(\mathrm{E})$ and richness (S) diversity indices of the collected sand flies within different localities were estimated using BioDap software (resource conservation, Fundy National Park Canada) as follows:

$$
\mathrm{H}=-\sum_{\mathrm{i}=1}^{5} \mathrm{Pi} \ln (\mathrm{Pi})
$$

$\mathrm{Pi}$ is the proportion of total number of species/total. $\mathrm{E}=\mathrm{H} / \log (\mathrm{S})$, where $\mathrm{S}$ is the total number of species in the community.

Similarity between different habitats was estimated using the Jaccard coefficient $\left(S_{i j}\right)$ formula: $S_{i j}=a /(a+b$ $+c)$, where a is the number of species present in both replicates, $\mathrm{b}$ is the number present in replicate I only and $\mathrm{c}$ is the number of species present in replicate $\mathrm{j}$.

Ethics - Verbal informed consent was obtained from human volunteers and from the heads of the households from which sand flies were collected. Sand flies were collected using CDC light traps, sticky traps and human volunteers. Protection of human volunteers in the endemic areas sampled was achieved using customary bed nets. Ethical clearance was obtained from the primary health unit of Al-Baha, Kingdom of Saudi Arabia.

\section{RESULTS}

Sand fly species composition - An overall total of 16,472 sand flies were collected from 12 stations representing six sectors of the Al-Baha province from 1996-1997 (Table I). The collected sand flies consisted of six species of Phlebotomus: Phlebotomus bergeroti, P. sergenti, Phlebotomus arabicus, Phlebotomus alexandri, P. papatasi and Phlebotomus orientalis and three of genus Sergentomyia: Sergentomyia clydei, Sergentomyia antennata and Sergentomyia tiberiadis. P. bergeroti was the most abundant and constituted $41.7 \%$ of the collected flies. The total number of males caught was higher than that of females, except for S. clydei, S. antennata and S. tiberiadis. The male/female ratios for different species were substantially different: $P$. bergeroti $=1.6, P$. sergenti $=1.7, P$. arabicus $=1.8, P$. alexandri $=1.3, P$. papatasi $=4.2$ and $P$. orientalis $=3.1$. For Sergentomyia species, the values for S. clydei, S. antennata and $S$. tiberiadis were $0.77,0.56$ and 0.57 , respectively. The study showed a markedly different distribution of the collected sand fly species across different sectors investigated 
TABLE I

Phlebotomine sand flies collected by CDC light traps (LT), sticky paper traps (ST) and aspiration (AS) from six sectors of the province of Al-Baha, Saudi Arabia, from January 1996-December 1997

\begin{tabular}{|c|c|c|c|c|c|c|c|c|}
\hline Species & $\begin{array}{l}\text { Collection } \\
\text { method }\end{array}$ & $\begin{array}{c}\text { Al-Dafear } \\
\mathrm{M} / \mathrm{F}\end{array}$ & $\begin{array}{l}\text { Al-Baha } \\
\mathrm{M} / \mathrm{F}\end{array}$ & $\begin{array}{l}\text { El Aqiq } \\
\mathrm{M} / \mathrm{F}\end{array}$ & $\begin{array}{l}\text { El Mandak } \\
\qquad \mathrm{M} / \mathrm{F}\end{array}$ & $\begin{array}{c}\text { Al-Mekowa } \\
\mathrm{M} / \mathrm{F}\end{array}$ & $\begin{array}{c}\text { Khelow } \\
\mathrm{M} / \mathrm{F}\end{array}$ & $\begin{array}{l}\text { Total } \\
\mathrm{M} / \mathrm{F}\end{array}$ \\
\hline \multirow{3}{*}{ Phlebotomus bergeroti } & $\mathrm{LT}$ & $40 / 71$ & $16 / 3$ & $355 / 368$ & $970 / 129$ & $334 / 238$ & $1211 / 818$ & $2926 / 1627$ \\
\hline & ST & $6 / 0$ & $22 / 1$ & $221 / 201$ & $175 / 52$ & $271 / 155$ & $422 / 198$ & $1117 / 607$ \\
\hline & AS & $12 / 7$ & $23 / 3$ & $44 / 12$ & $27 / 108$ & $37 / 86$ & $62 / 169$ & $205 / 385$ \\
\hline \multirow[t]{3}{*}{ Phlebotomus sergenti ${ }^{a}$} & $\mathrm{LT}$ & $51 / 30$ & $14 / 3$ & $92 / 44$ & $17 / 4$ & $188 / 73$ & $131 / 119$ & $493 / 273$ \\
\hline & $\mathrm{ST}$ & $63 / 16$ & $40 / 9$ & $25 / 41$ & $45 / 103$ & $210 / 157$ & $226 / 50$ & $609 / 376$ \\
\hline & AS & NA/NA & $1 / 0$ & $2 / 0$ & $2 / 9$ & $5 / 10$ & $13 / 6$ & $23 / 25$ \\
\hline \multirow[t]{3}{*}{ Phlebotomus arabicus } & $\mathrm{LT}$ & $128 / 30$ & $86 / 44$ & $120 / 36$ & $17 / 15$ & $163 / 67$ & $176 / 45$ & $690 / 237$ \\
\hline & ST & $52 / 31$ & $73 / 80$ & $30 / 29$ & $55 / 19$ & $103 / 52$ & $104 / 110$ & $417 / 321$ \\
\hline & AS & $5 / 7$ & $6 / 13$ & $0 / 3$ & $0 / 6$ & $3 / 13$ & $4 / 27$ & $18 / 69$ \\
\hline \multirow[t]{3}{*}{ Phlebotomus alexandri } & $\mathrm{LT}$ & NA/NA & NA/NA & $83 / 20$ & $71 / 55$ & $34 / 3$ & $32 / 41$ & $220 / 119$ \\
\hline & ST & NA/NA & NA/NA & $14 / 29$ & $25 / 37$ & $0 / 11$ & $0 / 7$ & $39 / 84$ \\
\hline & AS & NA/NA & NA/NA & $7 / 2$ & $6 / 8$ & $1 / 0$ & $2 / 1$ & $16 / 11$ \\
\hline \multirow[t]{3}{*}{ Phlebotomus papatasi } & $\mathrm{LT}$ & NA/NA & NA/NA & $247 / 29$ & $224 / 88$ & $151 / 23$ & $93 / 42$ & $715 / 182$ \\
\hline & ST & NA/NA & NA/NA & $294 / 18$ & $113 / 9$ & $102 / 5$ & $112 / 29$ & $621 / 61$ \\
\hline & AS & $0 / 3$ & NA/NA & $14 / 49$ & $11 / 12$ & $0 / 7$ & $5 / 4$ & $30 / 75$ \\
\hline \multirow[t]{3}{*}{ Phlebotomus orientalis } & $\mathrm{LT}$ & NA/NA & $27 / 0$ & $64 / 41$ & $33 / 14$ & $10 / 0$ & $52 / 0$ & $186 / 55$ \\
\hline & ST & NA/NA & $2 / 0$ & $11 / 1$ & $42 / 3$ & $13 / 0$ & $19 / 16$ & $87 / 20$ \\
\hline & AS & NA/NA & $2 / 1$ & $4 / 4$ & $3 / 8$ & $3 / 2$ & $2 / 0$ & $14 / 15$ \\
\hline \multirow[t]{3}{*}{ Sergentomyia clydei } & LT & $0 / 5$ & $0 / 9$ & $1 / 9$ & $1 / 5$ & $0 / 3$ & $7 / 22$ & $9 / 53$ \\
\hline & ST & $3 / 3$ & $4 / 7$ & $9 / 3$ & $8 / 8$ & $26 / 6$ & $8 / 4$ & $58 / 31$ \\
\hline & AS & $1 / 0$ & $\mathrm{NA} / \mathrm{NA}$ & $1 / 0$ & $1 / 4$ & $6 / 11$ & $2 / 2$ & $11 / 17$ \\
\hline \multirow[t]{3}{*}{ Sergentomyia antennata } & LT & $3 / 54$ & $1 / 41$ & $5 / 67$ & $58 / 53$ & $28 / 111$ & $96 / 148$ & $191 / 474$ \\
\hline & ST & $29 / 25$ & $50 / 31$ & $87 / 83$ & $25 / 19$ & $134 / 241$ & $34 / 110$ & $359 / 509$ \\
\hline & AS & NA/NA & $2 / 0$ & $3 / 2$ & $3 / 6$ & $3 / 7$ & $9 / 15$ & $20 / 30$ \\
\hline \multirow[t]{3}{*}{ Sergentomyia tiberiadis } & LT & $7 / 47$ & $18 / 21$ & $4 / 26$ & $36 / 58$ & $63 / 152$ & $76 / 132$ & $204 / 436$ \\
\hline & ST & $55 / 32$ & $12 / 44$ & $28 / 65$ & $34 / 155$ & $213 / 185$ & $66 / 186$ & $408 / 667$ \\
\hline & AS & $4 / 0$ & NA/NA & $4 / 3$ & $1 / 1$ & $5 / 3$ & $5 / 1$ & $19 / 8$ \\
\hline \multirow[t]{3}{*}{ Total } & LT & $229 / 237$ & $162 / 121$ & $971 / 640$ & $1427 / 421$ & $971 / 670$ & $1874 / 1367$ & $5634 / 3456$ \\
\hline & ST & $208 / 107$ & $203 / 172$ & $719 / 470$ & $522 / 405$ & $1072 / 812$ & $991 / 710$ & $3715 / 2676$ \\
\hline & AS & $22 / 17$ & $34 / 17$ & $79 / 75$ & $54 / 162$ & $63 / 139$ & $104 / 225$ & $356 / 635$ \\
\hline
\end{tabular}

$a$ : the species identity was revised in accord with the morphological character described by Depaquit et al. (1998). M: male; F: female; NA: not available.

in the study. CDC light trap collections accounted for 9090 specimens $(55.2 \%)$ of the total sand flies caught.

Sand fly population structure at different altitudes - There was a difference in the diversity of the sand fly fauna across different altitudes, as indicated by $\mathrm{H}$ values (Table II). From 800-1200 m altitude, the diversity was more significant. The S diversity was high at 800-1200 m altitude, with an $\mathrm{E}$ diversity $=0.74$. The relatively low $\mathrm{E}$ (0.73), even with high $\mathrm{S}$ at the altitude range of $0-200 \mathrm{~m}$, may be due to the dominance of $P$. bergeroti.

\section{TABLE II}

The Shannon-Weiner diversity index $(\mathrm{H})$, evenness $(\mathrm{E})$ and richness (S) for the sand fly species at different altitude ranges within the province of Al-Baha, Saudi Arabia

\begin{tabular}{lccc}
\hline Altitudes (m) & H & E & S \\
\hline $0-200$ & 1.60 & 0.73 & 9 \\
$800-1200$ & 1.73 & 0.74 & 9 \\
$\geq 2500$ & 1.69 & 0.86 & 7 \\
\hline
\end{tabular}



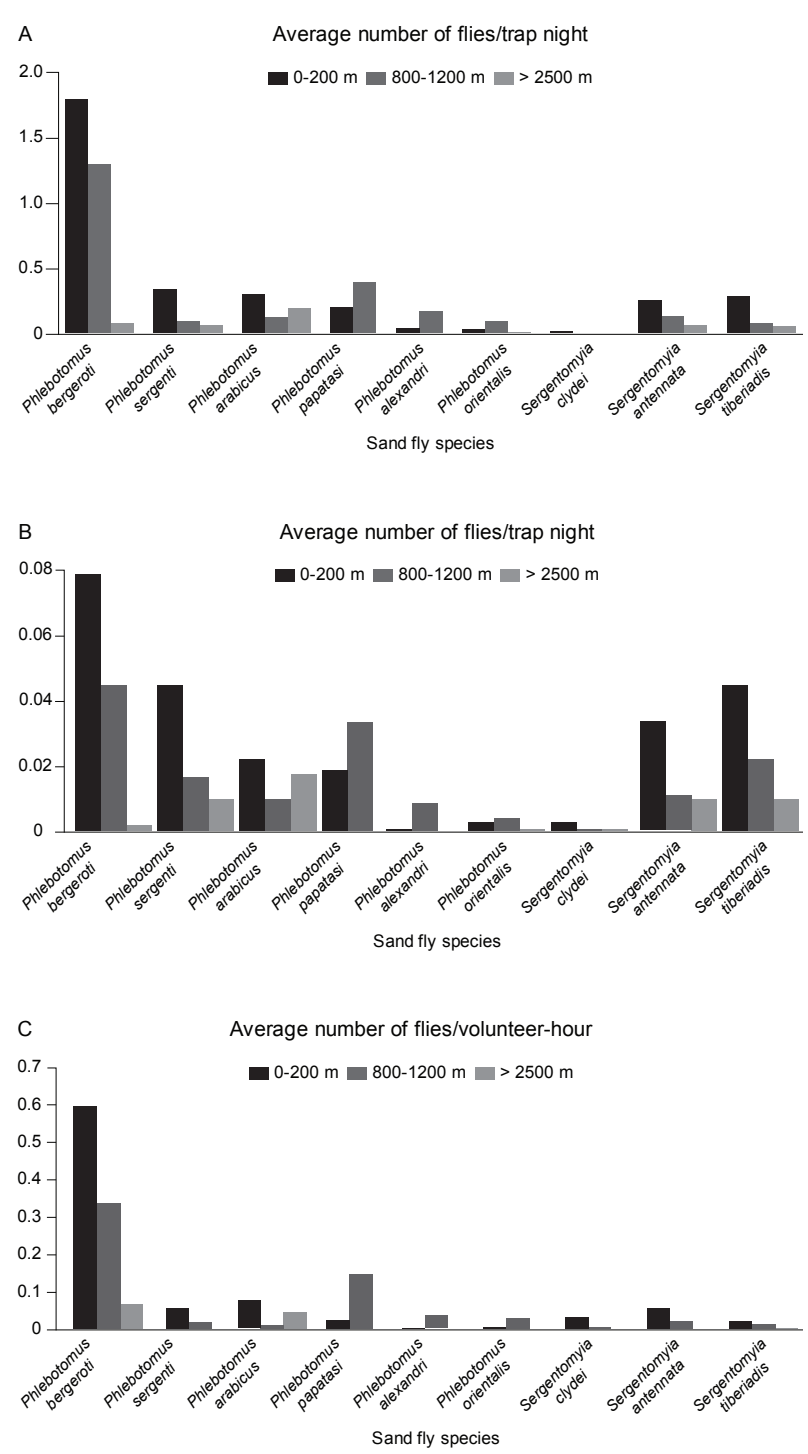

Fig. 2: correlation of different altitudes and the presence of sand fly species in the province of Al-Baha, Saudi Arabia, using different collection techniques. A: CDC light traps; B: sticky paper traps; C: aspiration off protected human volunteers.

The sand fly community similarities as measured by Jacard's coefficient $\left(\mathrm{I}_{\text {Jacard }}\right)$ indicated that the similarity of the sand fly communities was highest $(100 \%$ of the sand fly communities or $\mathrm{I}_{\text {Jacard }}=1$ ) between $0-200 \mathrm{~m}$ and 800 $1200 \mathrm{~m}$ altitude ranges and lowest $(0.78)$ between both $0-200$ and $\geq 2500 \mathrm{~m}$ or $800-1200 \mathrm{~m}$ and $\geq 2500 \mathrm{~m}$ altitude ranges. Using different collection methods, $P$. bergeroti, $P$. sergenti, P. arabicus, $P$. orientalis, $S$. clydei, S. antennata and $S$. tiberiadis were collected at all altitudes, whereas $P$. papatasi and $P$. alexandri were restricted to the 0-200 $\mathrm{m}$ and 800-1200 $\mathrm{m}$ altitude ranges (Fig. 2A-C).

Seasonal abundance and dynamics of sand flies - Fluctuations in the abundance of sand flies were followed at 12 stations, using CDC light traps, sticky traps and human bait from January 1996-December 1997.
Different species varied in seasonal activity patterns across different sites (Fig. 3A-F). Of the six Phlebotomus spp collected, four species (P. bergeroti, P. sergenti, $P$. arabicus and $P$. orientalis) were found each month. $P$. bergeroti, $P$. sergenti, $P$. arabicus and $P$. papatasi peaked mid-season (May-June) whereas the P. alexandri numbers peaked during the dry months (July-August) and the $P$. orientalis numbers peaked from AugustSeptember. Numbers of all sand fly species dropped markedly in November, except for $P$. alexandri, which increased in number in November, declined in December and reappeared in January.

Sand fly abundance inside and outside houses - P. bergeroti, $P$. papatasi and $P$. arabicus were the most abundant both inside houses (76.7\% of all sand flies) and outdoors (65\% of the catch) (Fig. 4). P. sergenti were found to land more on human volunteers outdoors than indoors (34/57).

Sand fly natural infection - Of the 2,213 dissected Phlebotomus females, blood was found in the gut of $1,022(44.6 \%)$. Only five of the sand flies were found to be naturally infected with Leishmania-like flagellates (Table III). The sand flies positive for Leishmania-like flagellate infection were found to belong to three species $[P$. bergeroti $(\mathrm{n}=3), P$. sergenti $(\mathrm{n}=1)$ and $P$. arabicus $(\mathrm{n}=1)]$. High infection rates were recorded in areas of low altitudes (3/913) and the overall infection rate in all monitored areas was $0.2 \%$.

\section{DISCUSSION}

The geographic location of Al-Baha contributes to the potential risk for CL in Saudi Arabia; it is also possible to contract infections from neighboring countries there. This study is a report of the results of an entomological survey of sand flies in Al-Baha province, Saudi Arabia. The goal of this report was to identify the sand fly vectors associated with CL-endemic areas of AlBaha province. Efforts were also made to identify the bionomics of the sand flies in the area. P. bergeroti, $P$. sergenti, $P$. arabicus, $S$. tiberiadis, $P$. papatasi and $S$. antennata were the most abundant species identified in the current study. The identified species were also reported in many parts of the kingdom of Saudi Arabia, such as Riyadh (Morsy \& al Seghayer 1992), Asir (Ibrahim \& Abdoon 2005), Qasim (el Sibae et al. 1993) and AlHassa (Al-Gindan et al. 1984). Dominance of one or two species of sand flies is a feature of many areas of Saudi Arabia (Ibrahim \& Abdoon 2005, El-Badry et al. 2008) and of some parts of the Middle East, including Egypt (El Sawaf et al. 1987, Fahmy et al. 2009, Shehata et al. 2009), Iraq (Seccombe et al. 1993, Coleman et al. 2007), Palestine (Sawalha et al. 2003) and Jordan (Kamhawi et al. 1991). The collected species reported here include the most important vectors of CL in the Middle East, which contribute to the persistence of the CL transmission cycle in Saudi Arabia. Here, P. papatasi was relatively less abundant than previously reported (El-Badry et al. 2008), which is likely due to the difference in community structure and nature of habitats sampled, i.e., mostly 

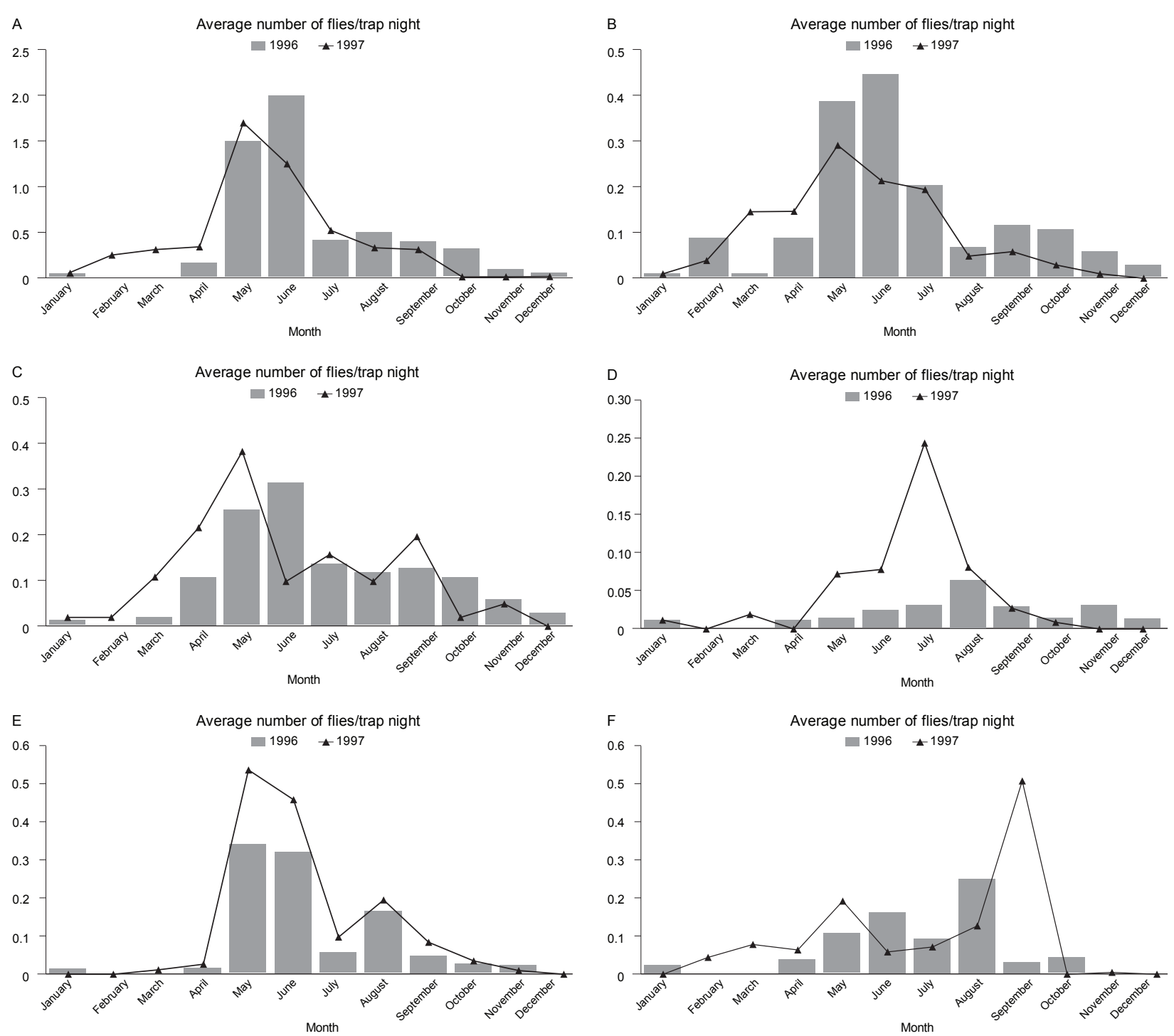

Fig. 3: seasonal abundance of Phlebotomus sand flies in different habitats of the province of Al-Baha, Saudi Arabia, during 1996-1997. A: Phlebotomus bergeroti; B: Phlebotomus sergenti; C: Phlebotomus arabicus; D: Phlebotomus alexandri; E: Phlebotomus papatasi; F: Phlebotomus orientalis.

wild. P. papatasi, the proven vector of L. major (Wahba et al. 1990, Shehata et al. 2009), was found to be widely distributed in peridomestic and domestic habitats (Janini et al. 1995, Kamal et al. 2003).

There was a remarkable difference in the diversity of the sand fly fauna across the different altitudes reported here, although altitude is not a selective factor for fly distribution (Karan et al. 2000). According to the distribution of the sand fly at different altitudes, two groups of sand fly fauna were determined: the first one in lower and median altitude ranges and the second at higher altitude. The species $\mathrm{S}$ and diversity were the highest at about $800-1200 \mathrm{~m}$, which could represent the transition between the lowland and the mountains (ecotone) in Al-Baha. P. papatasi, the proven vector of $L$. major, was collected at all altitudes, with maximum abundance at $800-1200 \mathrm{~m}$, an altitude at which a high prevalence of wet sores was observed. $P$.

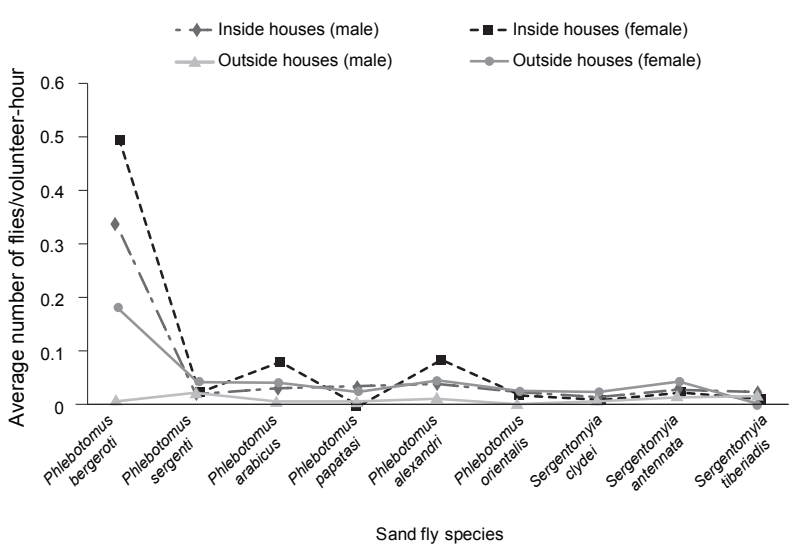

Fig. 4: relative abundance of Phlebotomus sand fly species inside and outside houses. Data was collected using human baits in different localities of the province of Al-Baha, Saudi Arabia, during 1996-1997. 


\section{TABLE III}

The dissected female sand flies, their physiological status and infection rate in different sectors of the province of Al-Baha, Saudi Arabia, during 1996-1997

\begin{tabular}{lcccc}
\hline Area & $\begin{array}{c}\text { Dissected females } \\
\mathrm{n}\end{array}$ & $\begin{array}{c}\text { Blood fed females } \\
\mathrm{n}(\%)\end{array}$ & $\begin{array}{c}\text { Parous females } \\
\mathrm{n}(\%)\end{array}$ & $\begin{array}{c}\text { Infected females } \\
\mathrm{n}(\%)\end{array}$ \\
\hline Al-Dafear & 87 & $24(27.6)$ & $13(14.9)$ & $0(0)$ \\
Al-Baha & 252 & $93(36.9)$ & $32(12.7)$ & $1^{a}(0.04)$ \\
El Aqiq & 578 & $271(46.9)$ & $83(14.3)$ & $1^{b}(0.04)$ \\
El Mandak & 383 & $183(47.8)$ & $42(11)$ & $0(0)$ \\
Al-Mekowa & 271 & $89(32.8)$ & $34(12.5)$ & $0(0)$ \\
Khelow & 642 & $362(56.4)$ & $141(22)$ & $3^{c}(0.13)$ \\
Total & 2,213 & $1,022(46.2)$ & $345(15.6)$ & -
\end{tabular}

a: Phlebotomus sergenti; $b$ : Phlebotomus arabicus; $c$ : Phlebotomus bergeroti.

sergenti and P. arabicus, the vectors of L. tropica (Svobodova et al. 2006), were collected from all altitudes, with maximum numbers at low altitude ranges.

The population dynamics of sand flies in Al-Baha were greatly affected by seasonal variations. Our results suggest that the highest activity of the collected sand fly species occurs between May-August. Such a pattern of seasonal abundance was observed in different localities of Al-Baha by El-Badry et al. (2008), in El-Nekheil and by other studies in Asir (Ibrahim \& Abdoon 2005) and in Hail (Bakr 1995), Saudi Arabia. Identifying the seasonal abundance of the collected species is of importance for prediction of the period of maximum risk for leishmaniasis transmission and for the successful implementation of a control program. Sand fly activity can vary within its geographical range depending on local factors, such as temperature, geographical barriers, habitat availability and the distribution and abundance of vertebrate hosts (Cross et al. 1996, Sawalha et al. 2003). The current study revealed three behavior scenarios for the collected sand fly species: $P$. bergeroti, $P$. papatasi and $P$. arabicus were most abundant indoors and were truly endophilic species, whereas $P$. sergenti was truly exophilic. The third pattern observed was that Sergentomyia spp and P. alexandri both seem to prefer open habitats, as previously reported by Lane et al. (1988) and Coleman et al. (2007).

To understand the role that each sand fly species can play in the maintenance of the transmission cycle, other factors regarding parity of the sand flies monitored were also studied. The parity rate is an essential parameter for estimating the vectorial capacity of the sand fly, especially if the biting rates of parous flies vary during the night and are somewhat less than those of nulliparous flies (Lewis et al. 1970). Natural infection of parous females by Leishmania promastigotes was confirmed using evidence from Giemsa stain impression smears and from zymodeme analysis. The parasites found were indistinguishable from those identified in human cases in the same area. The presence of infected flies throughout the year suggests that there is a continual presence of the reservoir host harboring the infection and suggests an overlap of high vector populations and high infection rates. There is a window of greatest infection risk for area residents, so we still need further investigation of host preference, anthroponotic behavior and vectorial efficiency of the sand fly vectors associated with endemic areas of Saudi Arabia and bordering countries. Naturally infected $P$. bergeroti, $P$. sergenti and $P$. arabicus provide additional information that may confirm that $P$. arabicus is associated with the dynamics of leishmaniasis in Al-Baha; this study outlines the importance of this species in epidemiology of the disease.

\section{ACKNOWLEDGEMENTS}

To Bahira M Elsawaf and Mohammed A Kenawy, for helpful comments and suggestions that really improved the manuscript, to the staff of primary health care, Ministry of Health, Al-Baha, KSA, for their contribution to the study design, selection of the study area, data collection and taking part in the study, especially to Mosleh El Ghobashi, Ibrahim Mesfer and Yahia Al-Zahrani, and to Abdallah Samy, for technical support in the manuscript writing and analysis of data.

\section{REFERENCES}

Al-Gindan Y, Abdul-Aziz O, Kubba R 1984. Cutaneous leishmaniasis in A1-Hassa, Saudi Arabia. Int J Dermatol 23: 194-197.

al-Zahrani MA, Peters W, Evans DA, Chin C, Smith V, Lane RP 1988. Phlebotomus sergenti, a vector of Leishmania tropica in Saudi Arabia. Trans R Soc Trop Med Hyg 82: 416.

al-Zahrani MA, Peters W, Evans DA, Smith V, Ching CI 1989. Leishmania infecting man and wild animals in Saudi Arabia. 5. Diversity of parasites causing visceral leishmaniasis in man and dogs in the south-west. Trans R Soc Trop Med Hyg 83: 503-509.

Bakr RF 1995. Survey and ecological study of sandflies in relation to dermal leishmaniasis, in Hail, Northern province, Saudi Arabia. Ain Shams Sci Bull 33: 375-389.

Büttiker W, Lewis DJ 1983. Insects of Saudi Arabia some ecological aspects of Saudi Arabian Phlebotomine sand flies (Diptera: Psychodidae). Fauna Saudi Arabia 5: 479-530.

Coleman RE, Burkett DA, Sherwood V, Caci J, Spradling S, Jennings BT, Rowton E, Gilmore W, Blount K, White CE, Putnam JL 2007. Impact of phlebotomine sand flies on U.S. Military operations at 
Tallil Air Base, Iraq: 2. Temporal and geographic distribution of sand flies. $J$ Med Entomol 44: 29-41.

Cross ER, Newcomb WW, Tucker CJ 1996. Use of weather and remote sensing to predict the geographic and seasonal distribution of Phlebotomus papatasi in southwest Asia. Am J Trop Med Hyg 54: 530-536.

Depaquit J, Léger N, Ferté H 1998. The taxonomic status of Phlebotomus sergenti Parrot, 1917, vector of Leishmania tropica (Wright, 1903) and Phlebotomus similis Perfiliev, 1963 (Diptera - Psychodidae). Morphologic and morphometric approaches. Biogeographical and epidemiological corollaries. Bull Soc Pathol Exot 91: 346-352.

El Sawaf BM, Shoukry A, El Said S, Lane RP, Kenawy MA, Beier JC, Abdel Sattar S 1987. Sand fly species composition along an altitudinal transect in Southern Sinai, Egypt. Ann Parasitol Hum Сотр 62: 467-473.

el Sibae MM, Eesa NM, Morsy TA 1993. Rodents and cutaneous leishmaniasis in Qasim, Saudi Arabia. J Egypt Soc Parasitol 23: 667-673.

El-Badry A, Al-Juhani A, Ibrahim el-K, Al-Zubiany S 2008. Distribution of sand flies in El-Nekheil province, in Al-Madinah Al-Munawwarah region, western of Saudi Arabia. Parasitol Res 103: 151-156.

Fahmy AR, Samy AM, Doha SA, Shehata MG 2009. Preliminary field investigations on Phlebotomine sandflies (Diptera: Psychodidae) from a recent cutaneous leishmaniasis focus in Northern-Sinai, Egypt. Egypt Acad J Biolog Sci 2: 9-15.

Ibrahim AA, Abdoon AM 2005. Distribution and population dynamics of Phlebotomus sand flies (Diptera: Psychodidae) in an endemic area of cutaneous leishmaniasis in Asir Region, Southwestern Saudi Arabia. J Entomol 2: 102-108.

Janini R, Saliba E, Khoury S, Oumeish O, Adwan S, Kamhawi S 1995. Incrimination of Phlebotomus papatasi as vector of Leishmania major in the southern Jordan Valley. Med Vet Entomol 9: 420-422.

Kamal HA, Doha SA, El-Hosary SS, Shehata MG, El Sawaf BM 2003. Human zoonotic cutaneous leishmaniasis and associated sand flies (Diptera: Psychodidae) in Sheikh Atiya village, southern Sinai, Egypt. J Egypt Soc Parasitol 33: 795-803.

Kamhawi S, Abdel-Hafez SK, Molyneux DH 1991. The behavior and dispersal of sandflies in Ras el Naqb, south Jordan with particular emphasis on Phlebotomus kazeruni. Parassitologia 33 (Suppl.): 307-314.

Karan D, Dubey S, Moreteau B, Parkash R, David JR 2000. Geographical clines for quantitative traits in natural populations of a tropical drosophilid: Zaprionus indanus. Genetica 108: 91-100.

Killick-Kendrick R, Leaney AJ, Peters W, Rioux JA, Bray RS 1985. Zoonotic cutaneous leishmaniasis in Saudi Arabia: the incrimination of Phlebotomus papatasi as the vector in the Al-Hassa oasis. Trans R Soc Trop Med Hyg 79: 252-255.

Lane RP 1986. The sand flies of Egypt (Diptera: Phlebotominae). Bull Br Mus Nat Hist (Ent) 52: 1-36.
Lane RP, Abdel-Hafez S, Kamhawi S 1988. The distribution of phlebotomine sandflies in the principal ecological zones of Jordan. Med Vet Entomol 2: 237-246.

Lewis D, Büttiker W 1982. Insects of Saudi Arabia: the taxonomy and distribution of Saudi Arabian Phlebotomus sand flies (Diptera: Psychodidae). Fauna Saudi Arabia 4: 353-397.

Lewis DJ 1982. A taxonomic review of the genus Phlebotomus (Diptera: Psychodidae). Bull Br Mus Nat Hist Entomol 45: 121-209.

Lewis DJ, Büttiker W 1980. Insects of Saudi Arabia, Diptera Fam. Psychodidae, Subfam. Phlebotominae. Fauna Saudi Arabia 2: 252-285.

Lewis DJ, Lainson R, Shaw JJ 1970. Determination of parous rates in Phlebotomine sandflies with special reference to Amazonian species. Bull Entomol Res 60: 209-219.

Morsy TA, al Gahtani YM, Faris RM 1991. Two abnormal cases of anthroponotic cutaneous leishmaniasis in Al Baha, Saudi Arabia. J Egypt Soc Parasitol 21: 675-678.

Morsy TA, al Seghayer SM 1992. A brief note on phlebotomine sandflies in Riyadh, Saudi Arabia. J Egypt Soc Parasitol 22: 437-440.

Mustafa MB, Hussein SM, Ibrahim EA, al-Seghayer SM, al Amri SA, Gradoni L 1994. Phlebotomus papatasi (Scopoli), vector of zoonotic cutaneous leishmaniasis in Riyadh province, Saudi Arabia. Trans R Soc Trop Med Hyg 88: 40.

Smart J, Jordan K, Whittick RJ 1965. Insect of medical importance, 4th ed., British Museum Natural History, Adlen Press Oxford, p. 286-288.

Sawalha SS, Shtayeh MS, Khanfar HM, Warburg A, Abdeen ZA 2003. Phlebotomine sand flies (Diptera: Psychodidae) of the Palestinian West Bank: potential vectors of leishmaniasis. J Med Entomol 40: 321-328.

Seccombe AK, Ready PD, Huddleston LM 1993. A catalogue of Old World phlebotomine sandflies (Diptera: Psychodidae, Phlebotominae). Occas Pap Syst Entomol 8: 1-57.

Shehata MG, Samy AM, Doha SA, Fahmy AR, Kaldas RM, Furman BD, Villinski JT 2009. First report of Leishmania tropica from a classical focus of L. major in North-Sinai, Egypt. Am J Trop Med Hyg 81: 213-218.

Svobodova M, Votypka J, Peckova J, Dvorak V, Nasereddin A, Baneth G, Sztern J, Kravchenko V, Orr A, Meir D, Schnur LF, Volf P, Warburg A 2006. Distinct transmission cycles of Leishmania tropica in 2 adjacent foci, Northern Israel. Emerg Infect Dis 12: 1860-1868.

Ungureanu EM 1974. Population dynamics and age grading of mosquitos. Bull World Health Organ 50: 317-321.

Wahba MM, Schnur LF, Morsy TA, Merdan A 1990. The characterization of Leishmania major from Phlebotomus papatasi (Scopoli) caught in northern Sinai, Egypt. Trans R Soc Trop Med Hyg 84: 785-786.

WHO - World Health Organization 2008. Report of the consultative meeting on cutaneous leishmaniasis, WHO, Geneva, 36 pp. 